\title{
The relationship between individual, social and national coping resources and mental health during the COVID-19 pandemic in the Netherlands
}

\begin{abstract}
BACKGROUND
The COVID-19 pandemic has a potential negative impact on mental health. Adopting the salutogenic model of health, this study examined the predictive value of personal (sense of coherence), social (social support, trust in institutions), and national (sense of national coherence) resources for mental health in the Netherlands during the COVID-19 pandemic.
\end{abstract}

\section{PARTICIPANTS AND PROCEDURE}

An online survey was administered in the Netherlands $(N=622)$ in April 2020. A multiple regression analysis was performed to test the predictive value of the resources for mental health.
RESULTS

Mental health was significantly predicted by the sense of coherence, social support and sense of national coherence, but not by trust in institutions. The results showed that personal and social resources were most strongly related to mental health.

\section{CONCLUSIONS}

The results suggest that mental health is predicted by various resources. Hence, strengthening resources seems vital in promoting mental health in times of crisis.

KEY WORDS

salutogenesis; psychology; health promotion; pandemic

ORGANIZATION - Health and Society, Social Sciences Group, Wageningen University, Wageningen, The Netherlands AUthors' CONTRiButions - A: Study design - B: Data collection - C: Statistical analysis - D: Data interpretation .

E: Manuscript preparation · F: Literature search · G: Funds collection

CORRESPonding AUthor - Sabina Super, Ph.D., Health and Society, Social Sciences Group, Wageningen University, Hollandseweg 1, 6706 KN Wageningen, The Netherlands, e-mail: sabina.super@wur.nl 


\section{BACKGROUND}

On the $12^{\text {th }}$ of March 2020, the World Health Organization classified the outbreak of COVID-19 as a pandemic; more than 3.5 million people were at that point infected by the virus and the number of confirmed deaths had passed 250,000. Globally, the COVID-19 pandemic adversely affects the mental health of people through both direct pathways (e.g., fear of attracting the virus or fear of experiencing serious health consequences) and indirect pathways (e.g., fear resulting from the economic crisis or depressive symptoms caused by social isolation) resulting in anxiety, stress and depressive symptoms (Torales et al., 2020). Although the pandemic is global, it appears that each country has developed its own way of managing the crisis, for example by enforcing a lockdown or by calling more upon citizens' responsibilities to take appropriate hygienic measures within an intelligent lockdown.

In the Netherlands, the first patients with COVID-19 appeared in a specific province in February 2020, after which the virus spread to other provinces as well (RIVM, 2020b). National measures were implemented in what the government called 'an intelligent lockdown'. These measures were developed in close collaboration with (scientific) experts and supported by the latest scientific insights. People's individual responsibility was called upon to take care of vulnerable people by practising social hygiene, social distancing, and working from home whenever possible. Schools were closed in mid March and professionals in so-called non-essential contact professions (e.g., hairdressers, massage therapists, restaurants and bars) had to stop their business. However, most shops were able to remain open, and people were allowed to go outside for recreational purposes, as long as they kept sufficient distance from other people. The police monitored whether citizens abided by the rules in the public space. As of today (May 2020), this policy seems to have efficiently flattened the hospitalization and COVID-19-related death curves (RIVM, 2020b). The Dutch government and scientific experts are working on an 'intelligent exit strategy', which means that very carefully restrictions can be alleviated.

Recently, the Trimbos Institute for Mental Health (2020) conducted a cross-sectional study on the impact of the governmental measures on people's mental health in the Netherlands. Although the sample was not representative of the Dutch population, the results suggest that, since the COVID-19 pandemic, one out of three people have experienced adverse mental health conditions. People who fear the COVID-19 pandemic suffer from the negative consequences, reporting high levels of anxiety, fear, sleeping problems, and even suicidal thoughts. Around half of the respondents reported needing help and support to deal with these stressors as not everyone was able to deal with stressors in a health-promoting way (Trimbos
Institute for Mental Health, 2020). Since an effective vaccine for COVID-19 has not yet been found, and the current measures of maintaining social distance and practising hygiene will not be lifted any time soon, it is very relevant to study what resources allow people to effectively deal with stressors and to support their mental health in the future.

The ability to cope with stressors reflects the central concept of the salutogenic model of health, namely the sense of coherence (Antonovsky, 1987). People with a strong sense of coherence are able to understand the stressor (i.e., comprehensibility), are able to select an appropriate strategy to deal with the stressor (i.e., manageability), and have a strong feeling that engaging with the stressor is a meaningful process (i.e., meaningfulness). There is ample evidence that a strong sense of coherence predicts better mental health (Moksnes \& Espnes, 2020), is associated with healthy lifestyle choices (Wainwright et al., 2008), improved physical health (Eriksson \& Lindström, 2006), and reduced mortality risk (Super et al., 2014). During the COVID-19 pandemic, the sense of coherence could be a personal resource enabling people to maintain optimal emotional, social and psychological wellbeing.

Next to personal resources, research suggests that social resources, such as social support from family, the community and the workplace, act as a buffer against adverse life events and support optimal mental health outcomes (Srensen et al., 2011). Moreover, social support and sense of coherence have a reciprocal relationship with each other, meaning that social support enhances sense of coherence levels (Pijpker et al., 2018) and that sense of coherence boosts levels of social support (Volanen et al., 2004). Another social resource that is likely to support healthy coping with stressors in times of COVID-19 is trust in institutions (e.g., media, government, hospitals) (Thoresen et al., 2018). Opinion polls suggested that more than $80 \%$ of the Dutch people supported the measures taken by the government (RIVM, 2020a). Hence, both social support and trust in institutions may protect mental health.

Finally, how people deal with stressors can be influenced by their perceptions of the strategies that are implemented, especially because every country takes different measures during the COVID-19 pandemic. This is captured in the sense of national coherence, posited by Mana et al. (2019), reflecting an enduring tendency to perceive one's national group as comprehensible, meaningful, and manageable. A strong sense of national coherence has been found to be an important factor for community resilience, especially in conflict areas (Sarid et al., in press), thereby potentially also having a positive influence on mental health.

The COVID-19 pandemic provides a unique opportunity to investigate which factors are important
Coping resources and mental health during the COVID-19 pandemic 
Sabina Super, Roald Pijpker, Kristel Polhuis to stay healthy in times of a pandemic crisis. This study aims to examine the predictive value of personal (sense of coherence), social (social support, trust in institutions), and national (sense of national coherence) resources for mental health in the $\mathrm{Ne}$ therlands during the COVID-19 pandemic. This study was conducted in parallel to a similar survey study in Israel (Mana \& Sagy, 2020), allowing for a crosscountry comparison of individual, social and national coping resources that play a role in dealing with the COVID-19 pandemic. The results reported in this study are based on data collected in the Netherlands.

\section{PARTICIPANTS AND PROCEDURE}

\section{PARTICIPANTS}

A cross-sectional study design was adopted to examine the predictive value of personal, social and national resources for mental health. Data were collected via an online survey developed in Qualtrics. Data were collected during one week in April 2020 (three weeks after announcement of the intelligent lock-down). Via social media and the personal networks of the research team, participants were invited to participate voluntarily in the survey. Inclusion criteria were that participants 1) had to be Dutch and be able to read Dutch, and 2) had to be 18 years or older. Ethical approval for this study was obtained via the Social Sciences Ethics Committee from the Wageningen University. Informed consent was asked at the start of the survey. It was not possible for participants to fill in the questionnaire without providing informed consent. A total of 622 Dutch participants completed the online survey.

\section{MEASUREMENTS}

Mental Health Continuum. To assess the mental health of the participants, 14 items of the Mental Health Continuum were administered including the three components of well-being: emotional, social, and psychological (Keyes, 2005). The questionnaire was adapted to the current context and based on the experiences the participants had over the last two weeks regarding positive mental health (e.g., feeling happy, feeling confident). Items could be scored from 1 (never) to 6 (every day). Internal consistency of the questionnaire was $\alpha=.91$. An average mental health score was computed.

Sense of coherence. The sense of coherence was assessed using the 13 items of the Orientation to Life Questionnaire (Antonovsky, 1987) on a 7-point Likert scale. The items explored the participants' perceptions of the world as comprehensible, meaningful, and manageable. Internal consistency of the questionnaire was $\alpha=.85$. An average score for sense of coherence was computed.

Social support. Five items on perceived feelings of support from different social environments (family, community/neighbourhood, virtual community, government institutions and workplace) were administered on a 5-point Likert scale from 1 (very much) to 5 (not at all). Internal consistency of the questionnaire was $\alpha=.69$ for the entire sample. An average score on social support was computed.

Trust in institutions. The general trust towards several institutions was assessed using a 9-item scale that included the following institutions: media, Prime Minister, police, government, legal courts, ministry of finance, ministry of health, health-care workers, and hospitals, the Dutch King. Trust in institutions was assessed on a 5-point Likert scale from 1 (very much) to 5 (not at all). Internal consistency of the questionnaire was $\alpha=.85$. An average score for trust in institutions was computed.

Sense of national coherence. The sense of national coherence was assessed using the 7 items developed by Mana et al. (2019). The items could be scored on a 7-point Likert scale from 1 (totally agree) to 7 (totally disagree) providing an interpretation of participants' perceptions of the Dutch society as comprehensible, meaningful, and manageable. Internal consistency of the questionnaire was $\alpha=.70$ for the entire sample. An average score for sense of national coherence was computed.

Demographic variables. Age, gender, family status, level of education, and political orientation were also measured in the survey.

\section{STATISTICAL ANALYSIS}

The data were analysed using the statistical package IBM SPSS Statistics 25. The internal consistency of the variables was obtained using Cronbach's $\alpha$. Descriptive statistics of the concepts were obtained. The distribution properties of the variables were inspected; all variables had a normal distribution. Correlation analysis was performed to assess the correlations between personal, social and national resources, and mental health. Consequently, a multiple linear regression analysis was conducted to examine the predictive value of personal, social and national resources for mental health. As the demographic characteristics of the sample were not representative of the Dutch population, weighting factors were determined for gender and educational level. Demographic data of the Dutch population were obtained via the Central Bureau of Statistics for March 2020. By convention, missing values were excluded listwise and pairwise, and assumptions were not violated. Most importantly, there were no issues regarding multicollinearity; all variance inflation factors were below 3 . 


\section{RESULTS}

\section{DESCRIPTIVE STATISTICS}

Concerning the demographic variables, the majority of the sample was female $(n=427,71 \%)$. The age of the respondents ranged from 19 to $88(M=45$, $S D=18)$. The vast majority was married or had a registered partnership $(n=357,59 \%)$, followed by people who were single $(n=219,36 \%)$, divorced $(n=22,4 \%)$, and widowed $(n=7,1 \%)$. Most people identified themselves as left-centre voters $(n=201,37 \%)$, left-wing voters $(n=183,34 \%)$ or right-centre voters $(n=136,25 \%)$, whereas only a minority of the sample identified themselves as right-wing voters ( $n=20,4 \%$ ). Regarding educational level, respondents had a vocational education $(n=115,19 \%)$, professional higher education $(n=240,40 \%)$ or university education ( $n=248,41 \%)$.

Table 1 represents the descriptive statistics of the variables. On average, respondents scored 4.37 on their mental health $(S D=0.88)$, which indicates relatively good mental health in the past two weeks. On average, the respondents scored high on personal (sense of coherence, $M=4.96, S D=0.95$ ), social (social support, $M=3.14, S D=0.82$; trust in institutions, $M=3.76, S D=0.58$ ) and national resources (sense of national coherence, $M=4.55, S D=0.79$ ) as well.

\section{MULTIPLE REGRESSIONS}

Table 1 and Figure 1 show the outcome of the regression analysis for mental health. The results of the regression analysis indicated that the model explained $52 \%$ of the variance and that the model was a significant predictor of mental health, $R^{2}=.52$, $[F(4,533)=144.88, p<.001]$. Mental health scores were significantly predicted by sense of coherence, social support, and sense of national coherence, but not by trust in institutions. Furthermore, the regression analysis showed that mental health was most strongly predicted by sense of coherence and social support. No significant differences in predictive values of the resources for mental health between leftand right-oriented voters were found.

\section{DISCUSSION}

This study aimed to examine the predictive value of personal (sense of coherence), social (social support, trust in institutions), and national (sense of national coherence) resources for mental health in the Netherlands during the COVID-19 pandemic. The results demonstrated that mental health was predicted most strongly by the sense of coherence and social support, and to a lesser extent by the sense of national coherence. The observation that sense of national coherence had a limited predictive value for mental health may reflect the individualistic character of the Dutch, which focuses strongly on the individual's responsibility to be healthy and cope well (Chin et al., 2000; Hofstede et al., 2010). This is supported by the fact that trust in institutions did not show a relationship with mental health. Interestingly, social support was a strong and significant predictor of mental health, indicating that perceiving support from the direct social environment is important for Dutch people in dealing with stressors. This suggests that it may be valuable to support bottom-up initiatives to combat loneliness and to support local social cohesion in times of crisis. Considering the intelligent lock-down that is currently employed in the Netherlands, such initiatives could be further stimulated within the safety of the COVID-19 measures of maintaining social distance.

The results strongly complement existing work on the relationship between sense of coherence and mental health outcomes. Our findings also align with Srensen et al. (2011), who showed that both sense of coherence and social support make a significant independent and shared contribution to the explained variance in mental health outcomes. However, much

\section{Table 1}

Linear model of predictors for mental health $(N=603)$

\begin{tabular}{lccccr}
\hline Predictor variables & $\mathrm{b}$ & \multicolumn{2}{c}{$95 \% \mathrm{Cl}$} & & $\beta$ \\
\cline { 3 - 5 } & & $\mathrm{LL}$ & $\mathrm{UL}$ & \\
\hline SOC & .47 & .41 & .53 & .51 & $<.001$ \\
SONC & .12 & .04 & .21 & .11 & .006 \\
Trust & .03 & -.09 & .14 & .02 & .670 \\
Social support & .35 & .28 & .42 & .32 & $<.001$ \\
\hline
\end{tabular}

Note. $\mathrm{b}$ - unstandardized regression coefficient, LL - lower limit, UL - upper limit, SOC - sense of coherence, SONC - sense of national coherence. 


\section{Figure 1}

Overview of the regression analysis for mental health with the standardized regression coefficients for the predictor variables

Sabina Super, Roald Pijpker, Kristel Polhuis

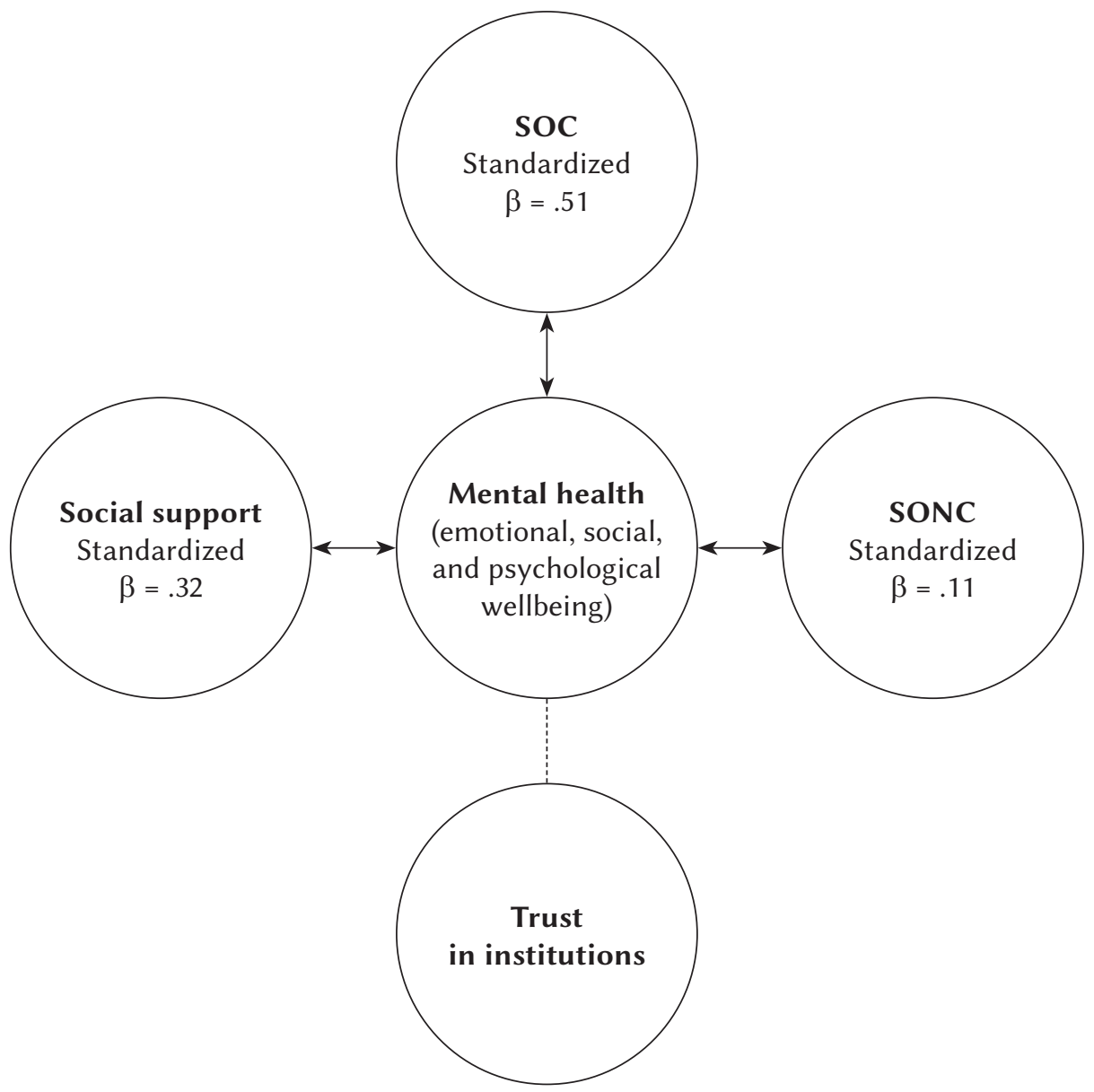

Note. SOC - sense of coherence; SONC - sense of national coherence. Double arrowed lines indicate that the variable significantly predicted mental health. Dashed lines indicate that the variable did not significantly predict mental health.

of the variance in mental health remained unexplained, which means that other resources could play a role as well. Related to this, sense of coherence can act as a predicter of mental health, as shown in this study, but research also shows that sense of coherence can moderate or mediate the relationship between stressors and mental health (Quehenberger \& Krajic, 2017). Future studies are encouraged to measure stressors and explore the moderating and mediating role(s) of the resources in facilitating mental health.

A similar study conducted in Israel at the same time as this study showed that "mental health was predicted only by personal resources among leftwing voters, while among the right-wing participants national resources were significant as well" (Mana \& Sagy, 2020). Yet, in the present study, the predictive value of personal, social and national resources for mental health did not differ between left- and rightoriented voters. This calls for further investigation of cross-cultural differences in dealing with a crisis, and how individual, social and national coping resources can play a varying role in this.

\section{STUDY LIMITATIONS}

This study was started ad hoc when the COVID-19 pandemic impacted health and wellbeing of citizens. Therefore, this study has a number of limitations that need to be considered as well. First of all, the sample was not representative of the Dutch population regarding gender and educational level. Therefore, we chose to weigh the data according to the distribution of these demographic variables in the Dutch population. However, readers should still be careful in generalizing these results to the entire population. Participants were mainly recruited via social media, which caused selection bias. Future studies are en- 
couraged to replicate the current research, preferably using online panels to recruit participants. A second concern is that all measures were self-reported, which brings many common methodological biases, such as response bias and the survey length, which may have influenced the results. We used validated scales to increase the internal validity of the results. A third limitation is that, although the participants were asked to confirm at the start of the questionnaire that they fulfilled the inclusion criteria and agreed to the informed consent, potentially Dutch speaking participants who were not from the Netherlands could have participated in the questionnaire. A final limitation is that the present study used a cross-sectional design to test the relationship between personal, social and national resources and mental health. It would be interesting to use longitudinal study designs to articulate better the direction of the relationships between resources and mental health.

\section{CONCLUSIONS}

The present study showed that personal (i.e., sense of coherence), social (i.e., social support) and national (i.e., sense of national coherence) resources can predict mental health. The predictive power of personal and social resources was higher for mental health than national resources. However, the sample was not representative of the Dutch population, and much variance in mental health remained unexplained, which means that other resources could play a role as well. With caution, it could be worthwhile to invest in people's sense of coherence and social support through bottom-up initiatives, thereby supporting effective coping with stressors in times of a pandemic crisis.

\section{RefERENCES}

Antonovsky, A. (1987). Unraveling the mystery of health. How people manage stress and stay well. Jossey-Bass.

Chin, N., Monroe, A., \& Fiscella, K. (2000). Social determinants of (un)healthy behaviors. Education for Health, 13, 317-328.

Eriksson, M., \& Lindström, B. (2006). Antonovsky's sense of coherence scale and the relation with health: a systematic review. Journal of Epidemiology and Community Health, 60, 376-381. https:// doi.org/10.1136/jech.2005.041616

Hofstede, G., Hofstede, G. J., \& Minkov, M. (2010). Cultures and organizations: Software of the mind. McGraw-Hill.

Keyes, C. L. M. (2005). Mental illness and/or mental health? Investigating axioms of the complete state model of health. Journal of Consulting and
Clinical Psychology, 73, 539-548. https://doi.org/ 10.1037/0022-006X.73.3.539

Mana, A., \& Sagy, S. (2020). Can political orientation explain mental health in the time of a global pandemic? Voting patterns, personal and national coping resources, and mental health during the Coronavirus crisis. Journal of Social and Clinical Psychology (in press).

Mana, A., Srour, A., \& Sagy, S. (2019). A sense of national coherence and openness to the "other's" collective narrative: The case of the Israeli-Palestinian conflict. Peace and Conflict: Journal of Peace Psychology, 25, 226-233. https://doi.org/10.1037/pac0000391

Moksnes, U. K., \& Espnes, G. A. (2020). Sense of coherence in association with stress experience and health in adolescents. International Journal of Environmental Research and Public Health, 17, 3003. https://doi.org/10.3390/ijerph17093003

Pijpker, R., Vaandrager, L., Bakker, E. J., \& Koelen, M. (2018). Unravelling salutogenic mechanisms in the workplace: The role of learning. Gaceta Sanitaria, 32, 275-282. https://doi.org/10.1016/j.gaceta. 2017.11.006

Quehenberger, V., \& Krajic, K. (2017). Applications of salutogenesis to aged and highly-aged persons: Residential care and community settings. In J. Pelikan (Ed.), The handbook of salutogenesis (pp. 325-335). Springer.

RIVM (2020a). Hoe reageren mensen in Nederland op het nieuwe coronavirus? [How do people in the Netherlands react to the new coronavirus?]. Retrieved from https://www.rivm.nl/coronaviruscovid-19/onderzoek/hoe-reageren-mensen-innederland-op-nieuwe-coronavirus

RIVM (2020b). Ontwikkeling COVID-19 in grafieken [Development of COVID-19 in graphs]. Retrieved from https://www.rivm.nl/coronavirus-covid-19/ grafieken

Sarid, A., Srour, A., \& Sagy, S. (in press). Sense of national coherence and willingness to concile: The case of the Israeli-Palestinian conflict before and after Gaza war in 2014. In F. Ferrari \& M. Leiner (Eds.), Encountering the suffering of the other. transdisciplinary perspectives from the DFG project "Hearts of Flesh-not Stone". Vandenhoeck and Ruprecht.

Srensen, T., Klungsyr, O., Kleiner, R., \& Klepp, O. M. (2011). Social support and sense of coherence: Independent, shared and interaction relationships with life stress and mental health. International Journal of Mental Health Promotion, 13, 27-44. https://doi. org/10.1080/14623730.2011.9715648

Super, S., Verschuren, W. M. M., Zantinge, E. M., Wagemakers, M. A. E., \& Picavet, H. S. J. (2014). A weak sense of coherence is associated with a higher mortality risk. Journal of Epidemiology and Community Health, 68, 411-417. https://doi.org/10.1136/jech2013-203085
Coping resources and mental health during the COVID-19 pandemic 
Sabina Super, Roald Pijpker, Kristel Polhuis
Thoresen, S., Birkeland, M. S., Wentzel-Larsen, T., \& Blix, I. (2018). Loss of trust may never heal. Institutional trust in disaster victims in a long-term perspective: Associations with social support and mental health. Frontiers in Psychology, 9, 1204. https://doi.org/10.3389/fpsyg.2018.01204

Torales, J., O’Higgins, M., Castaldelli-Maia, J. M., \& Ventriglio, A. (2020). The outbreak of COVID-19 coronavirus and its impact on global mental health. International Journal of Social Psychiatry, 66, 317320. https://doi.org/10.1177/0020764020915212

Trimbos Institute for Mental Health (2020). Neerslachtiger, meer slaapproblemen en gedachten aan de dood door corona [More depressed, more sleeping problems and thoughts of death from coronavirus]. Retrieved from https://www.trimbos.nl/actueel/ nieuws/bericht/neerslachtiger-meer-slaapproblemen-en-gedachten-aan-de-dood-door-corona

Volanen, S. M., Lahelma, E., Silventoinen, K., \& Suominen, S. (2004). Factors contributing to sense of coherence among men and women. European Journal of Public Health, 14, 322-330. https://doi.org/ 10.1093/eurpub/14.3.322

Wainwright, N. W. J., Surtees, P. G., Welch, A. A., Luben, R. N., Khaw, K. T., \& Bingham, S. A. (2008). Sense of coherence, lifestyle choices and mortality. Journal of Epidemiology and Community Health, 62, 829-831. https://doi.org/10.1136/jech.2007.066464 